\title{
Survey of bovine tuberculosis in Nigerian beef cattle
}

\author{
Ibrahim Ahmad ${ }^{1, *}$, Caleb Ayuba Kudi ${ }^{2}$, Alhaji Idris Abdulkadir ${ }^{2}$, S.N.A. Saidu ${ }^{2}$, Umar Mohammed Chafe ${ }^{3}$ and \\ Zainab Abdulmalik ${ }^{1}$ \\ ${ }^{1}$ Directorate of Animal Health and Livestock Development, Gusau, Zamfara, Nigeria \\ ${ }^{2}$ Departmet of Veterinary Medicine, Faculty of Veterinary Medicine, Ahmadu Bello University Zaria, Nigeria \\ ${ }^{3}$ Department of Veterinary Medicine, Faculty of Veterinary Medicine, Usmanu Danfodiyo University, Sokoto, \\ Nigeria
}

\begin{abstract}
Bovine tuberculosis (bTB) is a zoonotic disease caused by Mycobacterium tuberculosis complex (MTBC) that primarily affects cattle, but also other domestic and wild mammals. In Nigeria, abattoir monitoring of gross bTB lesions is the only control method being applied in all animals. This study aims to investigate tubercle bacilli infection in slaughtered cattle found with visible tuberculosis-like lesions. Lesions suggesting bTB were detected in 226 cattle during abattoir monitoring in Zamfara State, Nigeria. Tissue samples collected from the affected carcasses were subjected to Ziehl-Neelsen stain (ZN). Of the 226 carcasses with lesions, 37 (16.4\%) were positive by the ZiehlNeelsen stain $(\mathrm{ZN})$, and MTBC was detected from 34 (91.9\%) of the 37 ZN-positive samples. Molecular typing by region of difference (RD) deletion analysis revealed the genotype of Mycobacterium bovis, Mycobacterium caprae and Mycobacterium tuberculosis. Infection was most significantly associated with age of the animals (OR = 3.49; CI: 1.29-9.47 [ $p=0.002]$ ). The findings indicate a serious threat for health as well as for TB control in Nigeria.
\end{abstract}

Keywords: Bovine tuberculosis, Cattle, Nigeria.

\section{Introduction}

Bovine tuberculosis (bTB), caused by Mycobacterium tuberculosis complex (MTBC), is a zoonotic disease that primarily affects cattle, but also other domestic and wild mammals. Mycobacterium bovis is the bacilli within the MTBC mostly detected in tuberculous lesions from cattle (Krajewska et al., 2017; Waters et al., 2017; Yahyaoui-Azmi et al., 2017; Ku et al., 2018). Once infection is established in a herd, M. bovis can be transmitted between animals via aerosols, suckling, direct contact, and by sharing of contaminated water and feeds (El-Sayed et al., 2016; Yahyaoui-Azmi et al., 2017). Economic losses caused by bTB are mainly as a result of reduced productivity of affected animals and the condemnation (partial or total) of the carcasses at slaughter (Olea-Popelka et al., 2017).

BTB is endemic across sub-Saharan Africa due to the lack of proper financial resources that renders the control programs absent or ineffective. The disease significantly affects the livelihoods of rearing communities for its negative impacts on animal health, welfare and animal trade at international level. Only 7 out of 55 African countries followed adequate control programs, the remaining 48 countries including Nigeria control bTB inadequately or not at all (El-Sayed et al., 2016). Officially, postmortem examination of carcasses without systematic antemortem test-and-slaughter is the only current bTB control strategy being applied in Nigeria.

Previous studies (Ameen et al., 2008; Cadmus et al., 2009; Raufu and Ameh, 2010; Damina et al., 2011; Ahmad et al., 2017) undertaken at Nigerian abattoirs have reported bTB in cattle based on macroscopic lesions at an estimated range of $0.54 \%-6.1 \%$, indicating an increased trend in the prevalence. However, laboratory analyses to confirm infection in animals found with gross lesions are rarely performed unless for research purposes.

Diagnosis of bTB by identification of $M$. bovis has been enhanced with the aid of molecular techniques such as PCR and its variations (Carvalho et al., 2015). Deletion typing, as one of the PCR variants, has been found to be an important molecular tool in differentiating $M$. bovis from the other members of the MTBC, determined by discriminating the pattern (i.e. either presence or absence) of the genomic region of difference (Brosch et al., 2002; Mostowy et al., 2002; Warren et al., 2006; van Ingen et al., 2009). Hence, identification of tubercle bacilli responsible for the gross pathology is required for epidemiological investigations, control and eradication of bTB. This study therefore aimed at detecting tubercle bacilli in slaughtered cattle identified with gross TB lesions in an abattoir in Nigeria. 


\section{Materials and Methods Study area and sample collection}

The study was conducted in Gusau abattoir, Zamfara State, northwest of Nigeria. It is the only authorized slaughterhouse in the State that is manned by trained personnel (veterinarians).

Two hundred and twenty six cattle carcasses, examined according to the guidelines of Corner (1994), were identified with bovine TB-compatible lesions from April to June 2014. Lesion samples were collected in sterile containers for laboratory investigations, conveyed to Bacterial Zoonoses Laboratory at Ahmadu Bello University Zaria, Nigeria and stored at $-20^{\circ} \mathrm{C}$ until processing. Acid-fast bacilli (AFB) were identified using Ziehl-Neelsen stain (ZN), and RD deletion analysis was performed on all AFB positive samples. Individual animal data such as age was determined by dentition; breed and sex were also recorded.

\section{Tissue processing and Ziehl-Neelsen stain}

Prior to processing, frozen samples were thawed overnight, removed from containers, and put into sterile Petri dishes. Excess fatty tissues were trimmed off using sterile scalpel blade and forceps, before samples were macerated into tiny pieces. Approximately $5 \mathrm{~g}$ of sliced tissues were crushed using sterile Mortar and pestle before being homogenized in $10 \mathrm{ml}$ of sterile normal saline solution for $10 \mathrm{~min}$. Thereafter, homogenates were decontaminated with $2 \mathrm{ml}$ of $4 \%$ $\mathrm{NaOH}$ for $15 \mathrm{~min}$, neutralized with $1 \%(0.1 \mathrm{~N})$ hydrochloric acid $(\mathrm{HCl})$ using phenol red as an indicator, and concentrated by centrifugation at $3000 \mathrm{x}$ $\mathrm{g}$ for $15 \mathrm{~min}$. The supernatant was discarded, and an aliquot of the pellet from each whole-processed sample was used to prepare a smear for ZN. Loops of the pellet were gently smeared on a clean, grease-free microscopic slide, air-dried and heat-fixed on a hot plate at $70^{\circ} \mathrm{C}$ for $30 \mathrm{~min}$. $\mathrm{ZN}$ was performed to screen AFB positive samples as described by Lumb et al. (2013) with the following modifications: concentration of the acid-alcohol used was raised to $5 \%$ instead of $3 \%$ and decolourization time was extended from 5 to 10 min. The stained slides were then viewed under $\mathrm{x} 100$ objective of a light microscope to determine the presence and morphology of acid-fast bacilli.

\section{Determination of MTBC using RD deletion typing}

The homogenates of the samples that showed acid-fast bacilli were subjected to multiplex RD polymerase chain reaction (PCR). Thus genomic DNA was extracted from the homogenates $(n=37)$ according to the described protocols of Miller et al. (1997). Molecular identification of MTBC was performed in DNA-LABS at Kaduna Nigeria as previously described (Warren et al., 2006).

Briefly, PCR amplification was performed at a final reaction volume of $20 \mu \mathrm{l}$ consisting of $1 \mu \mathrm{l}$ DNA template re-suspended in HotStat PCR Premix (1 unit Taq DNA polymerase, $10 \mathrm{mM}$ Tris-HCl (pH 9.0), 30 $\mathrm{mM} \mathrm{KCl}, 250 \mu \mathrm{M}$ of each dNTPs, 1xPCR buffer and $1.5 \mathrm{mM} \mathrm{MgCl}_{2}$ ), $25 \mathrm{pM}$ of $0.5 \mu$ l each of the four 3sequence primers for the RD present or absent in the genome of members of the MTBC (Table 1) and $13 \mu \mathrm{l}$ sterile nuclease free water. Positive control with DNA template of reference-typed strain ( $M$. bovis BCG Pasteur) and negative control mixture (Master mix without DNA template) were included in the amplification run. The reaction was carried out in PTC$100^{\mathrm{TM}}$ Programmable Thermal Controller (MJ Research, Inc. USA) at the following conditions: initial denaturation at $95^{\circ} \mathrm{C}$ for 15 min followed by 45 cycles of denaturation at $94^{\circ} \mathrm{C}$ for $1 \mathrm{~min}$, annealing at $62^{\circ} \mathrm{C}$ for $1 \mathrm{~min}$ and extension at $72^{\circ} \mathrm{C}$ for $1 \mathrm{~min}$, with a final extension step at $72^{\circ} \mathrm{C}$ for $10 \mathrm{~min}$. Amplification products $(6 \mu \mathrm{l})$ were separated in 3\% agarose gels (Green Bio Research, USA) stained with $5 \mu$ ethidium bromide (Invitrogen, USA) at $120 \mathrm{~V}$ for 4 hours using Horizontal Gel Electrophoresis Apparatus (GIBCOBRL Model H5-Gaithersburg, USA). Gels were visualized, photographed and analyzed by comparing band sizes between M: DNA-Marker (100 bp Plus DNA ladder) (Bioneer, Inc. USA) and Lane 3onwards (samples amplified products). As previously described (Table 1), assessment of the presence or absence of RD by deletion analysis was used to differentiate species of the MTBC (Brosch et al., 2002; Warren et al., 2006; Mwakapuja et al., 2013).

After laboratory analyses, animals presumed tuberculous due to bTB-compatible lesions were classified as TB positive or negative based on positive/negative findings from $\mathrm{ZN}$ and deletion typing. Infection was confirmed in animals that were positive for both $\mathrm{ZN}$ and deletion typing, while negative in those initially identified only as acid-fast positive but showed no proper amplicons in deletion typing analysis.

\section{Statistical analysis}

Data obtained from field and laboratory was coded and analyzed using MS Excel 2016 and IBM SPSS Statistics software for Mac (Version 24) and expressed as frequencies and percentages, unless otherwise stated. Distribution of infection in different groups was compared by Chi-square or Fisher Exact Test. Robust univariate and multivariate logistic regression was used to evaluate the associations between infection, age, breed and sex of the animals in this study to demystify risk factor(s) for bovine TB. During multivariate regression analysis, adjustments were made for likely confounding factors (age and sex). Odds ratios (OR) with $95 \%$ confidence intervals (CI) were calculated to estimate the association between groups of interest to identify risk factors for infection. A $p$ value $<0.05$ was considered to have statistical significance. 
Table 1. Target region of difference (RD), primer sequences and corresponding amplicons for the identification of species from the M. tuberculosis complex (MTBC).

\begin{tabular}{|c|c|c|c|c|c|}
\hline $\begin{array}{c}\text { Target } \\
\text { RD }\end{array}$ & Primers sequence & M. bovis & M. tuberculosis & M. caprae & Reference \\
\hline 1 & AAGCGGTTGCCGCCGACCGACC & \multirow{3}{*}{$\begin{array}{l}\text { RD1 present } \\
\text { (146 bp) }\end{array}$} & \multirow{3}{*}{$\begin{array}{l}\text { RD1 present } \\
\text { (146 bp) }\end{array}$} & \multirow{3}{*}{$\begin{array}{l}\text { RD1 present } \\
\text { (146 bp) }\end{array}$} & \multirow{12}{*}{ Warren et al. (2006) } \\
\hline 1 & CTGGCTATATTCCTGGGCCCGG & & & & \\
\hline 1 & GAGGCGATCTGGCGGTTTGGGG & & & & \\
\hline 4 & ATGTGCGAGCTGAGCGATG & \multirow{3}{*}{$\begin{array}{l}\text { RD4 absent } \\
\text { (268 bp) }\end{array}$} & \multirow{3}{*}{$\begin{array}{l}\text { RD4 present } \\
\text { (172 bp) }\end{array}$} & \multirow{3}{*}{$\begin{array}{l}\text { RD4 present } \\
\text { (172 bp) }\end{array}$} & \\
\hline 4 & TGTACTATGCTGACCCATGCG & & & & \\
\hline 4 & AAAGGAGCACCATCGTCCAC & & & & \\
\hline 9 & CAAGTTGCCGTTTCGAGCC & \multirow{3}{*}{$\begin{array}{l}\text { RD9 absent } \\
\text { (108 bp) }\end{array}$} & \multirow{3}{*}{$\begin{array}{l}\text { RD9 present } \\
\text { (235 bp) }\end{array}$} & \multirow{3}{*}{$\begin{array}{l}\text { RD9 absent } \\
\text { (108 bp) }\end{array}$} & \\
\hline 9 & CAATGTTTGTTGCGCTGC & & & & \\
\hline 9 & GCTACCCTCGACCAAGTGTT & & & & \\
\hline 12 & GGGAGCCCAGCATTTACCTC & \multirow{3}{*}{$\begin{array}{l}\text { RD12 absent } \\
\text { (306 bp) }\end{array}$} & \multirow{3}{*}{$\begin{array}{l}\text { RD12 present } \\
\text { (369 bp) }\end{array}$} & \multirow{3}{*}{$\begin{array}{l}\text { RD12 absent } \\
\text { (306 bp) }\end{array}$} & \\
\hline 12 & GTGTTGCGGGAATTACTCGC & & & & \\
\hline 12 & AGCAGGAGCGGTTGGATATTC & & & & \\
\hline
\end{tabular}

bp: base pairs.

\section{Results}

The age, breed and sex distribution of infected animals is shown on Table 2.

Acid-fast bacilli were detected from thirty seven of all the cattle found with lesions (Fig. 1), while MTBC were identified from thirty four of thirty seven acid-fast positive cattle (Fig. 2a, b, c).

Thus the $\mathrm{ZN}$ and $\mathrm{RD}$ deletion typing positive rates were $16.4 \%$ (37/226) and 91.9\% (34/37) respectively. More so, $8 \%(3 / 37)$ of the acid-fast samples turned out to be negative for RD deletion typing.

All the samples confirmed as MTBC infection were positive to RD1 deletion typing, while $88.2 \%(n=30)$ were identified to be $M$. bovis as they were negative to RD4, RD9 and RD12 PCR.

In addition, three acid-fast samples (8.8\%) were identified to be $M$. caprae as they were positive to RD4 but negative to RD9 and RD12 PCR. While one (2.9\%) of the acid-fast samples was identified to be $M$. tuberculosis as it was positive to the RD4, RD9 and RD12 PCR.

The difference in the amplicons sizes indicates presence or absence of regions of difference in the genomic DNA amplified, which differentiates species of the Mycobacterium tuberculosis complex (Table 1). The odd of being infected is about four times higher in adult than juvenile animals $(\mathrm{OR}=3.94$; CI: 1.47 10.57).

Though not statistically significant $(p=0.19)$, Red Bororo and Sokoto Gudali breeds have 2.30 and 1.12 times higher potential of being infected than White Fulani breed. However, male animals have lesser chance of infection than females (Table 3).

A similar trend was observed when confounding parameters were adjusted (Table 4).

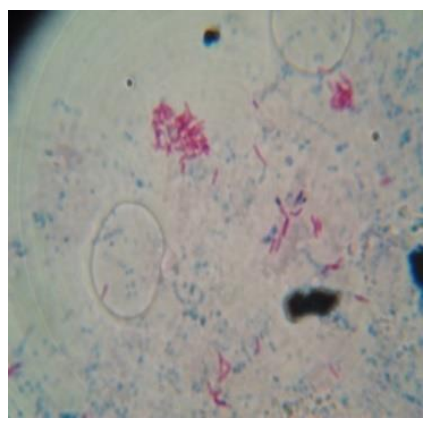

Fig. 1. Acid-fast bacilli appeared pinkish in a bluish background, detected in tuberculous lung from a cow (x100).

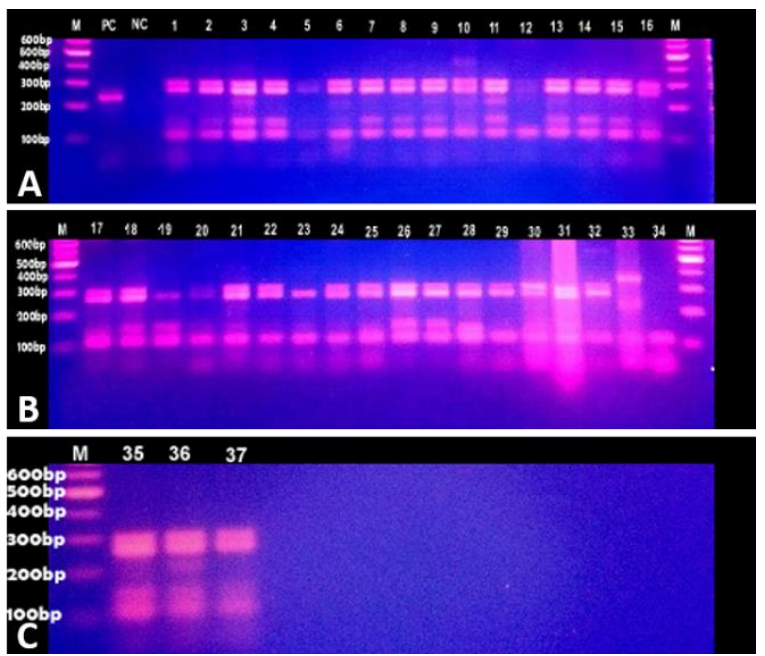

Fig. 2. (A, B, and C): Electrophoretic fractionation of amplicons in $3 \%$ agarose. $\mathrm{M}=100$ bp DNA ladder. $\mathrm{PC}=$ Positive control. NC $=$ Negative control. Lane 1-4, 6-11, 1318, 21, 22, $24-32$ and 35-37 = Mycobacterium bovis. Lane 19, 20 and $23=$ Mycobacterium caprae. Lane $33=$ Mybacterium tuberculosis. Lane 5, 12 and 34 = samples negative for RD PCR. 
Table 2. Summary table of acid-fast (AF) bacilli and Mycobacterium tuberculosis complex (MTBC) detected by ZN and Region of difference deletion typing from slaughtered cattle (with tuberculous lesions) in Nigeria.

\begin{tabular}{|c|c|c|c|c|c|c|c|c|c|c|c|}
\hline & \multirow{2}{*}{ Variables } & \multirow{2}{*}{$\mathrm{n}$} & \multicolumn{3}{|c|}{ AF Positive } & \multicolumn{3}{|c|}{ AF Positive with MTBC } & \multicolumn{3}{|c|}{ Mycobacterium spp. } \\
\hline & & & No. & $\%$ & $95 \% \mathrm{CI}$ & No. & $\%$ & $95 \% \mathrm{CI}$ & $M . b$. & M. $c$. & M. $t$. \\
\hline \multirow[t]{2}{*}{ Age } & Adult & 149 & 32 & 14.16 & $10.21-19.31$ & 30 & 78.38 & $\begin{array}{l}62.80- \\
88.61\end{array}$ & 27 & 3 & \\
\hline & Juvenile & 77 & 5 & 2.21 & $0.95-5.07$ & 4 & 13.51 & 5.91- 27.98 & 3 & & 1 \\
\hline \multirow{3}{*}{ Breed } & White Fulani & 129 & 25 & 11.06 & $7.61-15.82$ & 22 & 59.46 & $\begin{array}{l}43.49- \\
73.65\end{array}$ & 18 & 3 & 1 \\
\hline & Sokoto Gudali & 78 & 8 & 3.54 & $1.80-6.83$ & 8 & 21.62 & $\begin{array}{l}11.39- \\
37.20\end{array}$ & 8 & & \\
\hline & Red Bororo & 19 & 4 & 1.77 & $0.69-4.46$ & 4 & 10.81 & 4.29- 24.71 & 4 & & \\
\hline \multirow[t]{2}{*}{ Sex } & Female & 147 & 29 & 12.83 & $9.08-17.82$ & 27 & 72.97 & $\begin{array}{c}57.02- \\
84.60\end{array}$ & 23 & 3 & 1 \\
\hline & Male & 79 & 8 & 3.54 & $1.80-6.83$ & 7 & 18.92 & $9.48-34.20$ & 7 & & \\
\hline
\end{tabular}

(n): number of tuberculous cattle investigated; (CI): Exact binomial confidence intervals; (M. b.): Mycobacterium bovis; (M. c.): Mycobacterium caprae; (M. t.): Mycobacterium tuberculosis.

Table 3. Univariate analysis of factors associated with the presence of acid-fast (AF) bacilli in tuberculous cattle slaughtered at an abattoir in Nigeria.

\begin{tabular}{|c|c|c|c|c|c|c|c|}
\hline & \multirow{2}{*}{ Variables } & \multicolumn{3}{|c|}{ Tuberculous cattle } & \multirow{2}{*}{ OR } & \multirow{2}{*}{$95 \% \mathrm{CI}$} & \multirow{2}{*}{$p$-value } \\
\hline & & AF positive & AF negative & Total & & & \\
\hline \multirow{2}{*}{ Age } & Juvenile & 5 & 72 & 77 & 1 & & 0.004 \\
\hline & Adult & 32 & 117 & 149 & $3.94 *$ & $1.47-10.57$ & \\
\hline \multirow{3}{*}{ Breed } & White Fulani & 25 & 104 & 129 & 1 & & 0.190 \\
\hline & Sokoto Gudali & 8 & 70 & 78 & 1.12 & $0.34-3.67$ & \\
\hline & Red Bororo & 4 & 15 & 19 & 2.30 & $0.612-8.64$ & \\
\hline \multirow{2}{*}{ Sex } & Female & 29 & 118 & 147 & 1 & & 0.089 \\
\hline & Male & 8 & 71 & 79 & 0.46 & $0.20-1.06$ & \\
\hline
\end{tabular}

(OR): odds ratio; $(\mathrm{CI})$ : confidence interval; $(*)$ : Significant at $p<0.05$.

Table 4. Multivariate logistic regression model for the presence of acid-fast (AF) bacilli in tuberculous cattle slaughtered at an abattoir in Nigeria.

\begin{tabular}{llcccc}
\hline & Variables & AF Positive & Adjusted odds ratio & $95 \%$ CI & Likelihood ratio test \\
\hline \multirow{2}{*}{ Age } & Adult & 32 & $3.49 *$ & $1.29-9.47$ & 0.002 \\
& Juvenile & 5 & 1 & & 0.19 \\
\multirow{3}{*}{ Breed } & White Fulani & 25 & 1 & & \\
& Sokoto Gudali & 8 & 1.11 & $0.33-3.76$ & 0.06 \\
& Red Bororo & 4 & 1.75 & $0.45-6.80$ & \\
Sex & Female & 29 & 1 & & $0.25-1.46$ \\
\hline
\end{tabular}

(CI): confidence interval; $(*)$ : Significant at $p<0.05$.

There is no difference in odd ratio in the rate of infection across ages and breed among acid-fast (AF) positive cattle with MTBC infection, but a nonstatistical significance $(p=0.53)$ with reduced odd of infection was observed for male cattle $(\mathrm{OR}=0.52$; $\mathrm{CI}$ : 0.04-6.58) (Table 5).

This non-significant odd was reduced (Adjusted OR = 0.11; CI: 0.005-2.55) after controlling for age and breed of the animals (Table 6). There were significantly increased odds of infection among female, adult, Sokoto Gudali and Red Bororo cattle. Although age of the animals retained a statistically significant association $(p=0.004 ; 0.002)$, breed and sex are not significant factors in bovine TB infection $(p=0.19$; 0.06).

Therefore, this shows by implication that age of animals is the main predictor associated with much higher levels of tubercle bacilli infection. 
Table 5. Univariate analysis of factors associated with the presence of Mycobacterium tuberculosis complex (MTBC) infection in tuberculous cattle slaughtered at an abattoir in Nigeria.

\begin{tabular}{|c|c|c|c|c|c|c|}
\hline & \multirow{2}{*}{ Variables } & \multicolumn{2}{|c|}{ Acid-fast positive cattle } & \multirow{2}{*}{ OR } & \multirow{2}{*}{$95 \% \mathrm{CI}$} & \multirow{2}{*}{$p$-value } \\
\hline & & MTBC infection & No MTBC infection & & & \\
\hline \multirow{2}{*}{ Age } & Adult & 29 & 3 & 1 & & 0.63 \\
\hline & Juvenile & 5 & & 0 & 0 & \\
\hline \multirow{3}{*}{ Breed } & White Fulani & 22 & 3 & 1 & & 0 \\
\hline & Sokoto Gudali & 8 & & 2203 & 0 & \\
\hline & Red Bororo & 4 & & 1 & 0 & \\
\hline \multirow{2}{*}{ Sex } & Female & 27 & 2 & 1 & & 0.53 \\
\hline & Male & 7 & 1 & 0.52 & $0.04-6.58$ & \\
\hline
\end{tabular}

(OR): odds ratio; $(\mathrm{CI})$ : confidence interval.

Table 6. Multivariate logistic regression model for Mycobacterium tuberculosis complex (MTBC) infection in tuberculous cattle slaughtered at an abattoir in Nigeria.

\begin{tabular}{|c|c|c|c|c|c|}
\hline & Variables & $\begin{array}{l}\text { Acid-fast positive cattle with } \\
\text { MTBC infection }\end{array}$ & Adjusted odds ratio & $95 \% \mathrm{CI}$ & $\begin{array}{c}\text { Likelihood ratio } \\
\text { test }\end{array}$ \\
\hline \multirow{2}{*}{ Age } & Adult & 29 & 1 & & 0.34 \\
\hline & Juvenile & 5 & 0 & 0 & \\
\hline \multirow{3}{*}{ Breed } & White Fulani & 22 & 1 & & 0.29 \\
\hline & Sokoto Gudali & 8 & 4679 & 0 & \\
\hline & Red Bororo & 4 & 0.83 & 0 & \\
\hline \multirow{2}{*}{ Sex } & Female & 27 & 1 & & 0.62 \\
\hline & Male & 7 & 0.11 & $0.005-2.55$ & \\
\hline
\end{tabular}

(CI): confidence interval.

\section{Discussion}

Postmortem examination of carcasses in abattoirs detects only the more advanced forms of tuberculosis. Gross visible lesions in bTB developed as immune response tries to wall off the infection whereas early stages of the disease can easily be missed out, but this is avoidable if ante-mortem tests are also employed. Quite possibly, errors do occur in macroscopic lesions analyses of bTB-like pathology in abattoirs, in which case, diseased animals are slaughtered early and with recent infection (Carvalho et al., 2015).

However, tubercle bacilli were isolated from cattle with no visible lesions suggesting that $M$. bovis can be detected from cattle with or without lesions (Ku et al., 2018).

The proportion of samples positive by acid-fast staining (16.4\%) was low as compared to the about 30\% reported from a different part of Nigeria (Chukwu et al., 2013), and also lower than the 58\% reported elsewhere in Africa (Koro et al., 2013). This may be related to the adjusted concentration of acid-alcohol solution (5\% instead of the regular 3\%) and extended decolorization time of 10 min employed during the staining procedure in the present study. This might have helped to rule out other weak acid-fast non-tuberculous mycobacteria.
This study has shown that $92 \%$ of the acid-fast organisms to be $M$. tuberculosis complex, a figure higher than the $79.6 \%$ reported using deletion typing in Nigeria (Damina et al., 2011) and 68\% reported from Morocco (Yahyaoui-Azmi et al., 2017), but close to the 92.6\% reported from Ethiopia (Ameni et al., 2010). Most of the lesions found in this study are caused by $M$. bovis, similar to the findings reported from abattoirs in Morocco by Yahyaoui-Azmi et al. (2017).

Similarly, a study in Morocco found M. bovis and M. caprae in lesions from cattle (Yahyaoui-Azmi et al., 2017), whereas previous studies in Nigeria, Cameroon, Ethiopia, Zambia, and India found M. tuberculosis in tuberculous lesions from cattle (Damina et al., 2011; Aylate et al., 2013; Malama et al., 2014; Alemu et al., 2016; Egbe et al., 2016; Anne et al., 2017). Furthermore, infection with human tubercle bacilli among domesticated animals occurs mainly in urban areas, where human and animals coexist in the same microenvironment (Krajewska et al., 2017).

Krajewska et al. (2012) reported a case of an active TB in a Polish woman that eventually transmitted Mycobacterium tuberculosis to a calf in her farm. $M$. tuberculosis could be transmitted to cattle through various routes including inhalation and ingestion of 
feeds contaminated by sputum from infected farmers (Ameni et al., 2013; Alemu et al., 2016).

Our study revealed the risk of having bTB to be significantly associated with the age of the animal. This finding agrees with the published observations made elsewhere in Africa (Dejene et al., 2016; Egbe et al., 2016).

From our findings, female animals appear to have a higher risk of infection than males, similar to the findings of Worku et al. (2016) in Ethiopia. This might be due to the stress induced by calving that makes cows immunologically weak, and more vulnerable to infection than bulls.

The present study has also shown that Red Bororo and Sokoto Gudali breeds appear to have a higher risk (not significant) of contracting bTB as compared to White Fulani breed.

Cattle breed has been considered among other factors to be associated with the persistence of bovine TB infection (Alvarez et al., 2014).

Thus it requires a breed substitution of increased host resistance, among other viable options, to limit the spread of infection between herds and regions (Richardson et al., 2016).

The evidence of $M$. tuberculosis infection in cattle highlights a serious public health concern, suggesting a bi-directional transmission between animals and man. In certain non-industrialized nations, bTB is recognized as a public health problem due to persistent direct contact of humans with animal reservoir hosts and consumption of poorly processed animal products. In Nigeria, animals are not housed in segregated holdings but share both space and resources with man. This narrows the gap between species aggravating intra- and inter-species interactions, thus enhancing TB transmission through close repeated contacts and food chain.

\section{Conclusion}

This study has documented a high occurrence of $M$. bovis in beef cattle, with older animals having increased risk of bTB infection in Nigeria.

There is therefore the need for sound control and eradication programs in the country, as well as improved standards of meat inspection. In addition to reducing transmission through food chains and direct contact, there is also a need to intensify efforts on public enlightenment campaigns regarding potential dangers of the disease.

\section{Acknowledgements}

All staff of Bacterial Zoonoses Laboratory (Department of Veterinary Public Health and Preventive Medicine, Ahmadu Bello University Zaria Nigeria) and that of DNA-Labs Kaduna, Nigeria are thanked for their technical assistance.

\section{Conflict of interest}

The authors declare that there is no conflict of interest.

\section{References}

Ahmad, I., Kudi, C.A., Abdulkadir, A.I. and Saidu, S.N.A. 2017. Occurrence and distribution of bovine TB pathology by age, sex, and breed of cattle slaughtered in Gusau abattoir, Zamfara State. Trop. Anim. Health Prod. 49(3), 583-589.

Alemu, J., Mamo, G., Ameni, G. and Pal, M. 2016. Molecular epidemiology of bovine tuberculosis in cattle and its public health implication in Gambella region, Ethiopia. Mol. Microbiol. Res. 6(1), 1-5.

Alvarez, J., Perez, A., Marques, S., Bezos, J., Grau, A., de la Cruz, M., Romero, B., Saez, J. L., del Rosario Esquivel, M., del Carmen Martinez, M., Minguez, O., de Juan, L. and Dominguez, L. 2014. Risk factors associated with negative in-vivo diagnostic results in bovine tuberculosis-infected cattle in Spain. BMC Vet. Res. 10, 14. Doi: https://doi.org/10.1186/1746-6148-10-14.

Ameen, S.A., Adedeji, O.S., Raheem, A.K., Liegh, O.O., Rafi'u, T.A. and Ige, A.O. 2008. Current status of bovine tuberculosis in Ogbomoso area of Oyo State. Middle-East J. Sci. Res. 3(4), 207-210.

Ameni, G., Desta, F. and Firdessa, R. 2010. Molecular typing of Mycobacterium bovis isolated from tuberculosis lesions of cattle in north eastern Ethiopia. Vet. Rec. 167, 138-141.

Ameni, G., Tadesse, K., Hailu, E., Deresse, Y., Medhin, G., Aseffa, A., Hewinson, G., Vordermeier, M. and Berg, S. 2013. Transmission of Mycobacterium tuberculosis between farmers and cattle in Central Ethiopia. PLoS ONE 8(10):e76891. Doi: https://doi.org/10.1371/journal.pone.0076891.

Anne, N.S., Ronald, B.S.M., Senthil Kumar, T.M.A., Kannan, P. and Thangavelu, A. 2017. Molecular identification of Mycobacterium tuberculosis in cattle. Vet. Microbiol. 198, 81-87.

Aylate, A., Shah, S.N., Aleme, H. and Gizaw, T.T. 2013. Bovine tuberculosis: prevalence and diagnostic efficacy of routine inspection procedure in Woldiya municipality abattoir north Wollo zone, Ethiopia. Trop. Anim. Health Prod. 45(3), 855-864.

Brosch, R., Gordon, S.V., Marmiesse, M., Brodin, P., Buchrieser, C., Eiglmeier, K., Garnier, T., Gutierrez, C., Hewinson, G., Kremer, K., Parsons, L.M., Pym, A.S., Samper, S., van Soolingen, D. and Cole, S.T. 2002. A new evolutionary scenario for the Mycobacterium tuberculosis complex. Proc. Natl. Acad. Sci. U.S.A. 99, 3684-3689. https://doi.org/10.1073/pnas.052548299.

Cadmus, S.I., Adesokan, H.K., Jenkins, A.O. and van Soolingen, D. 2009. Mycobacterium bovis and $M$. tuberculosis in goats, Nigeria. Emerg. Infect. Dis. 15, 2066-2067.

Carvalho, R.C.T., Furlanetto, L.V., Maruyama, F.H., de Araujo, C.P., Barros, S.L.B., Ramos, C.A.N., Dutra, V., de Araujo, F.R., Paschoalin, V.M.F., 
Nakazato, L. and Figueiredo, E.E.S. 2015. Evaluation of the efficiency of nested q-PCR in the detection of Mycobacterium tuberculosis complex directly from tuberculosis-suspected lesions in postmortem macroscopic inspections of bovine carcasses slaughtered in the state of Mato Grosso, Brazil. Meat Sci. 106, 11-15.

Chukwu, I.D., Chukwu, C.O.C., Kandakai-Olukemi, Y.T., Owolodun, O., Nwosuh, C., Agada, G.O., Audu, B.J. and Chollom, S.C. 2013. Detection of Mycobacterium tuberculosis complex in lung specimen of slaughtered cattle and goats by a DNA based multiplex PCR and Ziehl-Neelsen methods in Jos, Nigeria. Br. Microbiol. Res. J. 3(4), 550-556.

Corner, L.A. 1994. Postmortem diagnosis of Mycobacterium bovis infection in cattle. Vet. Microbiol. 40, 53-63.

Damina, M.S., Owoludun, O.A., Chukwukere, S., Ameh, J.A. and Aliyu, M.M. 2011. The use of deletion analysis in the detection of Mycobacterium bovis, Mycobacterium tuberculosis and Mycobacterium africanum among slaughtered cattle in Plateau State. Nig. Vet. J. 32(1), 9-15.

Dejene, S.W., Heitkonig, I.M.A., Prins, H. H.T., Lemma, F.A., Mekonnen, D.A., Alemu, Z.E., Kelkay, T.Z. and de Boer, W.F. 2016. Risk factors for bovine tuberculosis (bTB) in cattle in Ethiopia. PLoS ONE 11(7), e0159083. Doi: 10.1371/journal.pone.0159083.

Egbe, N.F., Muwonge, A., Ndip, L., Kelly, R.F., Sander, M., Tanya, V., Ngu Ngwa, V., Handel, I.G., Novak, A., Ngandalo, R., Mazeri, S., Morgan, K.L., Asuquo, A. and Bronsvoort, B.M. de C. 2016. Abattoir-based estimates of mycobacterial infections in Cameroon. Sci. Rep. 6, 24320. Doi: $10.1038 /$ srep24320.

El-Sayed, A., El-Shannat, S., Kamel, M., CastanedaVazquez, M.A. and Castaneda-Vazquez, H. 2016. Molecular epidemiology of Mycobacterium bovis in humans and cattle. Zoonoses Public Health 63, 251264.

Koro, K.F., Bouba, Foko, E., Ngatehou, A.F., Eyangoh, S. and Etoa, F.-X. 2013. First insight into the current prevalence of bovine tuberculosis in cattle slaughtered in Cameroon: the case of main abattoirs of Yaounde and Douala. Br. Microbiol. Res. J. 3(3), 272-279.

Krajewska, M., Kozinska, M., Zwolska, Z., Lipiec, M., Augustynowicz-Kopec, E. and Szulowski, K. 2012. Human as a source of tuberculosis for cattle. First evidence of transmission in Poland. Vet. Microbiol. 159, 269-271.

Krajewska, M., Weiner, M. and AugustynowiczKopec, E. 2017. Animal tuberculosis as a potential danger to men. Health Prob. Civil. 11(1), 10-14. https://doi.org/10.5114/hpc.2017.65520.
Ku, B.K., Jeon, B.-Y., Kim, J.M. Jang, Y.-B., Lee, H., Choi, J.Y., Jung, S.C., Nam, H.-M., Park, H. and Cho, S.-N. 2018. Investigation of bovine tuberculosis outbreaks by using a trace-back system and molecular typing in Korean Hanwoo beef cattle. J. Vet. Sci. 19(1), 45-50.

Lumb, R., Van Deun, A., Bastian, I. and Fitz-Gerald, M. 2013. Laboratory Diagnosis of Tuberculosis by Sputum Microscopy, The Handbook. SA Pathology: Adelaide, South Australia, pp: 26-30.

Malama, S., Munyeme, M., Mbulo, G., Muwonge, A., Shamputa, I.C., Djonne, B., Godfroid, J. and Johansen, T.B. 2014. Isolation and molecular characterization of Mycobacterium tuberculosis from humans and cattle in Namwala District, Zambia. Ecohealth 11, 564-570.

Miller, J., Jenny, A., Rhyan, J., Saari, D. and Suarez, D. 1997. Detection of Mycobacterium bovis in formalin-fixed paraffin-embedded tissues of cattle and elk by PCR amplification of an IS6110 sequence specific for Mycobacterium tuberculosis complex organisms. J. Vet. Diagn. Invest. 9, 244249.

Mostowy, S. Cousins, D., Brinkman, J., Aranaz, A. and Behr, M.A. 2002. Genomic deletions suggest a pylogeny for the Mycobacterium tuberculosis complex. J. Infect. Dis. 186, 74-80.

Mwakapuja, R.S., Makondo, Z.E., Malakalinga, J., Moser, I., Kazwala, R.R. and Tanner, M. 2013. Molecular characterization of Mycobacterium bovis isolates from pastoral livestock at Mikumi-Selous ecosystem in the eastern Tanzania. Tuberc. Edinb. Scotl. 93, 668-674.

Olea-Popelka, F., Muwonge, A., Perera, A., Dean, A.S., Mumford, E., Erlacher-Vindel, E., Forcella, S., Silk, B.J., Ditiu, L., El Idrissi, A., Raviglione, M., Cosivi, O., LoBue, P. and Fujiwara, P.I. 2017. Zoonotic tuberculosis in human beings caused by Mycobacterium bovis-a call for action. Lancet Infect. Dis. 17, e21-25

Raufu, I.A. and Ameh, J.A. 2010. Prevalence of bovine tuberculosis in Maiduguri Nigeria: an abattoir study. Bull. Anim. Health Prod. Afr. 58, 119-123.

Richardson, I.W., Berry, D.P., Wiencko, H.L., Higgins, I.M., More, S.J., McClure, J., Lynn, D.J. and Bradley, D.G. 2016. A genome-wide association study for genetic susceptibility to Mycobacterium bovis infection in dairy cattle identifies a susceptibility QTL on chromosome 23. Genet. Sel. Evol. 48, 19. Doi: https://doi.org/10.1186/s12711016-0197-x.

van Ingen, J., de Zwaan, R., Dekhuijzen, R., Boeree, M. and van Soolingen, D. 2009. Region of difference 1 in nontuberculous mycobacterium species adds a phylogenetic and taxonomical character. J. Bacteriol. 191(18), 5865-5867. 
Warren, R.M., Gay van Pittius, N.C., Barnard, M., Hesseling, A., Engelke, E., Kock, M.D., Gutierrez, M.C., Chege, G.K., Victor, T.C., Hoal, E.G. and van Helden, P.D. 2006. Differentiation of Mycobacterium tuberculosis complex by PCR amplification of genomic regions of difference. Int. J. Tuberc. Lung Dis. 10, 818-822.

Waters, W.R., Voredermeier, H.M., Rhodes, S., Khatri, B., Palmer, M.V., Maggioli, M.F., Thacker, T.C., Nelson, J.T., Thomsen, B.V., Robbe-Austerman, S., Garcia, D.M.B., Schoenbaum, M.A., Camacho, M.S., Ray, J.S., Esfandiari, J., Lambotte, P., Greenwald, R., Grandison, A., Sikar-Gang, A. and Lyashchenko, K.P. 2017. Potential for rapid antibody detection to identify tuberculous cattle with non-reactive tuberculin skin test results. BMC Vet. Res. 13(1), 164. Doi: https://doi.org/10.1186/s12917-017-1085-5.

Worku, A., Abreham, S., Halilu, M., Mamo, G., Ameni, G. and Tsegaye, S. 2016. Cross-sectional study and comparison of different diagnostic methods of bovine tuberculosis in Gondar Elfora Abattoir, Ethiopia. Mycobact. Dis. 6, 3. Doi:10.4172/21611068.1000218.

Yahyaoui-Azmi, H., Aboukhassib, H., Bouslikhane, M., Berrada, J., Rami, S., Reinhard, M., Gagneux, S., Feldmann, J., Borrell, S. and Zinstag, J. 2017. Molecular characterization of bovine tuberculosis strains in two slaughterhouses in Morocco. BMC Vet. Res. 13(1), 272. 